\title{
Monitoring of the 2015 Villarrica Volcano Eruption by Means of DLR's Experimental TET-1 Satellite
}

\author{
Simon Plank ${ }^{1, *(\mathbb{D})}$, Michael Nolde ${ }^{1}$, Rudolf Richter ${ }^{2}{ }^{(1)}$, Christian Fischer $^{3}$, Sandro Martinis ${ }^{1}$, \\ Torsten Riedlinger ${ }^{1}$, Elisabeth Schoepfer ${ }^{1}$ and Doris Klein ${ }^{1}$ (D) \\ 1 German Remote Sensing Data Center, German Aerospace Center (DLR), 82234 Oberpfaffenhofen, Germany; \\ Michael.Nolde@dlr.de (M.N.); Sandro.Martinis@dlr.de (S.M.); Torsten.Riedlinger@dlr.de (T.R.); \\ Elisabeth.Schoepfer@dlr.de (E.S.); Doris.Klein@dlr.de (D.K.) \\ 2 Remote Sensing Technology Institute, German Aerospace Center DLR, 82234 Oberpfaffenhofen, Germany; \\ Rudolf.Richter@dlr.de \\ 3 Institute of Optical Sensor Systems, German Aerospace Center DLR, 12489 Berlin, Germany; \\ C.Fischer@dlr.de \\ * Correspondence: simon.plank@dlr.de; Tel.: +49-8153-28-3460
}

Received: 17 July 2018; Accepted: 28 August 2018; Published: 30 August 2018

\begin{abstract}
Villarrica Volcano is one of the most active volcanoes in the South Andes Volcanic Zone. This article presents the results of a monitoring of the time before and after the 3 March 2015 eruption by analyzing nine satellite images acquired by the Technology Experiment Carrier-1 (TET-1), a small experimental German Aerospace Center (DLR) satellite. An atmospheric correction of the TET-1 data is presented, based on the Advanced Spaceborne Thermal Emission and Reflection Radiometer (ASTER) Global Emissivity Database (GDEM) and Moderate Resolution Imaging Spectroradiometer (MODIS) water vapor data with the shortest temporal baseline to the TET-1 acquisitions. Next, the temperature, area coverage, and radiant power of the detected thermal hotspots were derived at subpixel level and compared with observations derived from MODIS and Visible Infrared Imaging Radiometer Suite (VIIRS) data. Thermal anomalies were detected nine days before the eruption. After the decrease of the radiant power following the 3 March 2015 eruption, a stronger increase of the radiant power was observed on 25 April 2015. In addition, we show that the eruption-related ash coverage of the glacier at Villarrica Volcano could clearly be detected in TET-1 imagery. Landsat-8 imagery was analyzed for comparison. The information extracted from the TET- 1 thermal data is thought be used in future to support and complement ground-based observations of active volcanoes.
\end{abstract}

Keywords: volcanic thermal anomalies; change detection; Villarrica Volcano; small satellites; FireBIRD; TET-1

\section{Introduction}

\subsection{Villarrica Volcano}

Villarrica Volcano $\left(39^{\circ} 25^{\prime} 12^{\prime \prime} \mathrm{S}, 71^{\circ} 55^{\prime} 48^{\prime \prime} \mathrm{W}\right)$ is one of the most active volcanoes of the South Andes Volcanic Zone. This volcano belongs to the currently eight volcanoes on Earth with confirmed active lava lakes [1]. The other seven are Kilauea (Halema'uma'u crater, Hawaii [2]), Ambrym (Vanuatu [3]), Masaya (Nicaragua [4]), Nyiragongo (Democratic Republic of Congo [5]), Erta 'Ale (Ethiopia [6]), Erebus (Antarctica [7]), and recently observed since 2014 Nyamuragira (Democratic Republic of Congo $[8,9])$.

Villarrica Volcano is a basaltic-andesitic stratovolcano with a height of $2847 \mathrm{~m}$ above sea level (a.s.l.). Its summit is covered by approximately $30 \mathrm{~km}^{2}$ of large glaciers, according to measurements 
taken in 2007 [10]. Based on infrasound measurements performed by Ripepe et al. [11] and gas composition investigations performed by Shinohara and Witter [12] both aforementioned groups suggest that at Villarrica Volcano degassing occurs very close to equilibrium with the magma and not by bursting of small gas bubbles at the surface of the magma column as occurs at other open-system volcanoes e.g., Stromboli. Over 50 historical eruptions are reported at Villarrica Volcano since the 16th century. These historic eruptions have ranged from effusive lava-producing eruptions to explosive eruptions up to the Volcanic Eruption Index (VEI) '3' [13]. According to Palma et al. [14], spattering and associated Strombolian eruptions as well as fire fountains have been observed at Villarrica Volcano.

Since the last eruptive episode in 1984, an actively degassing lava lake of width approximately $20 \mathrm{~m}$ to $30 \mathrm{~m}$, located at depths of $50 \mathrm{~m}$ to over $150 \mathrm{~m}$ within the funnel shaped summit crater [15], has filled the crater $[1,9,10]$. Although the summit crater of Villarrica Volcano has a diameter of approximately $150 \mathrm{~m}$, measurements based on inclinometer and laser range finder performed in 2000 and 2001 showed that the vent in the crater floor that leads to the surface of the lava lake has a diameter of only approximately $2 \mathrm{~m}$ to $30 \mathrm{~m}$ [9]. Measurements by Goto and Johnson [16], performed in January 2010, showed that the lava lake was located within a cylindrical cavity approximately $24 \mathrm{~m}$ below a $65 \mathrm{~m}$ diameter spatter roof overhang, which grew from the repeated agglutination and accumulation of ejected spatter. The diameter of the vent in the roof was approximately $10 \mathrm{~m}$ [16].

In this article we analyzed the active period before and after the 3 March 2015 eruption. During the eruption, which began at 03:08 on 3 March 2015 local Chile time (07:08 Coordinated Universal Time UTC) and lasted $55 \mathrm{~min}$, a volume of approximately $4.7 \pm 1.0$ million $\mathrm{m}^{3}$ erupted [17]. This is classified as a VEI '2' eruption, and produced intense tephra fallout, scoria flows, and a $20 \mathrm{~km}$ long lahar [18].

\subsection{Satellite-Based Thermal Remote Sensing of Volcanoes}

Satellite-based thermal remote sensing of volcanoes aims at (1) the early detection of volcanic activity to support decision makers and civil security authorities with respect to early warning activities $[19,20]$ and $(2)$ the monitoring of the spatiotemporal evolution of the volcanic eruptions to enhance our understanding of volcanic processes (see the reviews [21-24]).

To perform the first aim on a global scale, Earth observation satellite missions with a high temporal repetition rate and a large spatial coverage, such as the Moderate Resolution Imaging Spectroradiometer (MODIS) or Sentinel-3, are required. For instance, Wright et al. [25] described an automated MODIS data-based hotspots detection processor for near real-time thermal monitoring of volcanoes (MODVOLC). Kervyn et al. [26] proposed an updated version (MODLEN) that is also able to detect cooler lava, which was not possible with MODVOLC. For example, MODLEN enables the monitoring of the Tanzanian volcano Oldoinyo Lengai which erupts natro-carbonite lava at temperatures of $\sim 585^{\circ} \mathrm{C}$. Coppola et al. $[27,28]$ developed the Middle InfraRed Observation of Volcanic Activity (MIROVA) system, an enhancement of the aforementioned MODVOLC and MODLEN approaches.

Spampinato et al. [29] compared, at the Nyiragongo lava lake, ground measurements of FLIR infrared cameras and Spinning Enhanced Visible and Infrared Imager (SEVIRI) satellite data. Both observations showed similar values of the measured radiant power.

Blackett [30] showed the capabilities of thermal Landsat-8 imagery for analysis of volcanic activity, based on a case study of the Paluweh Volcano, Indonesia in April 2013.

The Technology Experiment Carrier-1 (TET-1), a small experimental German Aerospace Center (DLR) satellite, does not provide a continuous global coverage. However, due to its higher spatial resolution and higher sensitivity with regards to thermal anomalies, a more detailed analysis of volcanic activity is possible than with data from the aforementioned satellite missions. Section 2.1 provides more details on TET-1. Fischer et al. [31] demonstrated the high temperature event detection capabilities of TET- 1 by showing the detection of the volcanic hotspot at the 22 February 2015 acquisition as one example. Zakšek et al. [32] investigated the August-November 2014 Stromboli Volcano eruption by combining TET-1 imagery and thermal ground-based observations. 
In this study we analyzed a time series of nine TET-1 thermal images that were acquired before and after the 3 March 2015 Villarrica Volcano eruption (cf. Table 1). The temperature, area coverage, and radiant power of the detected thermal hotspots were derived at subpixel level and compared with observations derived from MODIS and Visible Infrared Imaging Radiometer Suite (VIIRS) data. In addition, to show a further application of TET-1 imagery in the field of volcano monitoring, the eruption-related ash coverage of the glacier at Villarrica Volcano was investigated by means of TET-1 imagery and the results were compared with higher resolution multispectral data from Landsat-8.

Table 1. Satellite imagery analyzed; MS = Multispectral.

\begin{tabular}{ccccc}
\hline Acquisition Date \& Time & Local Time, Chile & Satellite & Sensor Type & $\begin{array}{c}\text { MODIS Water Vapor } \\
\text { Acquisition Date \& Time }\end{array}$ \\
\hline 22 February 2015, 14:29 UTC & $10: 29$ & Landsat- 8 & MS, thermal & - \\
22 February 2015, 17:23 UTC & $13: 23$ & TET-1 & Thermal & 22 February 2015, 18:10 UTC \\
9 March 2015, 04:32 UTC & $00: 32$ & TET-1 & Thermal & 9 March 2015, 03:45 UTC \\
9 March 2015, 17:31 UTC & $13: 31$ & TET- 1 & Thermal & 9 March 2015, 19:05 UTC \\
10 March 2015, 14:29 UTC & $10: 29$ & Landsat-8 & MS, thermal & - \\
12 March 2015, 04:35 UTC & $00: 35$ & TET-1 & Thermal & 12 March 2015, 04:15 UTC \\
12 March 2015, 17:32 UTC & $13: 32$ & TET-1 & Thermal & 12 March 2015, 15:20 UTC \\
21 March 2015, 04:36 UTC & $00: 36$ & TET-1 & Thermal & 21 March 2015, 04:10 UTC \\
26 March 2015, 14:29 UTC & $10: 29$ & Landsat-8 & MS, thermal & - \\
27 March 2015, 17:33 UTC & $14: 33$ & TET-1 & Thermal & 27 March 2015, 18:50 UTC \\
25 April 2015, 04:35 UTC & $00: 35$ & TET-1 & Thermal & 25 April 2015, 03:05 UTC \\
25 April 2015, 17:49 UTC & $13: 49$ & TET-1 & Thermal & 25 April 2015, 18:20 UTC \\
\hline
\end{tabular}

${ }^{1}$ TET-1 scenes used for calibration (cf. Section 2.2.2).

\section{Materials and Methods}

\subsection{Satellite Data}

A time series of nine TET-1 thermal images acquired before and during the March/April 2015 eruption of Villarrica Volcano were analyzed (Table 1). In addition, three Landsat-8 scenes were used for validation purposes. Moreover, the thermal hotspots derived by the VIIRS and by MODIS were used as reference for the comparison described in Section 3.2.

TET-1 is the first of two satellites of DLR's FireBIRD mission. TET-1 was launched in July 2012, followed by BIROS (Berlin InfraRed Optical System) in June 2016. Both satellites are flying sun-synchronously in a low-Earth orbit at approximately $500 \mathrm{~km}$ altitude. The repetition rate of one satellite was approximately five days, depending on its geographic location. Nowadays, with both satellites in orbit, the potential repetition rate is less than three days with $\pm 30^{\circ}$ across track acquisitions. The sensors operate two infrared cameras, one in the mid wave infrared (MWIR) and one in the long wave infrared (LWIR), as well as a three-channel camera in the visible (VIS: RED and GREEN) and near infrared (NIR). The MWIR, LWIR, and RED channel are installed in nadir position, while the GREEN and NIR channel are oriented off-nadir (Table 2).

Table 2. Characteristics of the TET-1 cameras.

\begin{tabular}{ccc}
\hline Channel & Wavelength $(\mu \mathrm{m})$ & Looking Angle $\left(^{\circ}\right)$ \\
\hline GREEN & $0.460-0.560$ & $6^{\circ}$ forward \\
RED & $0.565-0.725$ & Nadir \\
NIR & $0.790-0.930$ & $6^{\circ}$ backward \\
MWIR & $3.400-4.200$ & Nadir \\
LWIR & $8.500-9.300$ & Nadir \\
\hline
\end{tabular}

TET-1 operates a push broom sensor system with a ground sampling distance of $178 \mathrm{~m}$ for the thermal channels. This corresponds to a pixel resolution of $356 \mathrm{~m}$ due to staggering. The MWIR channel of TET-1 is more suitable for the detection of high temperature events than LWIR, since higher 
temperature events have a higher radiant power at the shorter wavelengths according to the Wien's displacement law.

Landsat- 8 is the latest satellite of the Landsat series launched on 11 February 2013 by the National Aeronautics and Space Administration (NASA) and operated by the United States Geological Survey (USGS). Landsat-8 acquires multispectral (VIS, NIR, and short wave infrared (SWIR)) imagery with a $30 \mathrm{~m}$ spatial resolution, panchromatic imagery with $15 \mathrm{~m}$ resolution, and LWIR imagery with $100 \mathrm{~m}$ resolution.

\subsection{Methods}

Figure 1 shows the processing workflow which is described in the Sections 2.2.1-2.2.3 in more detail.

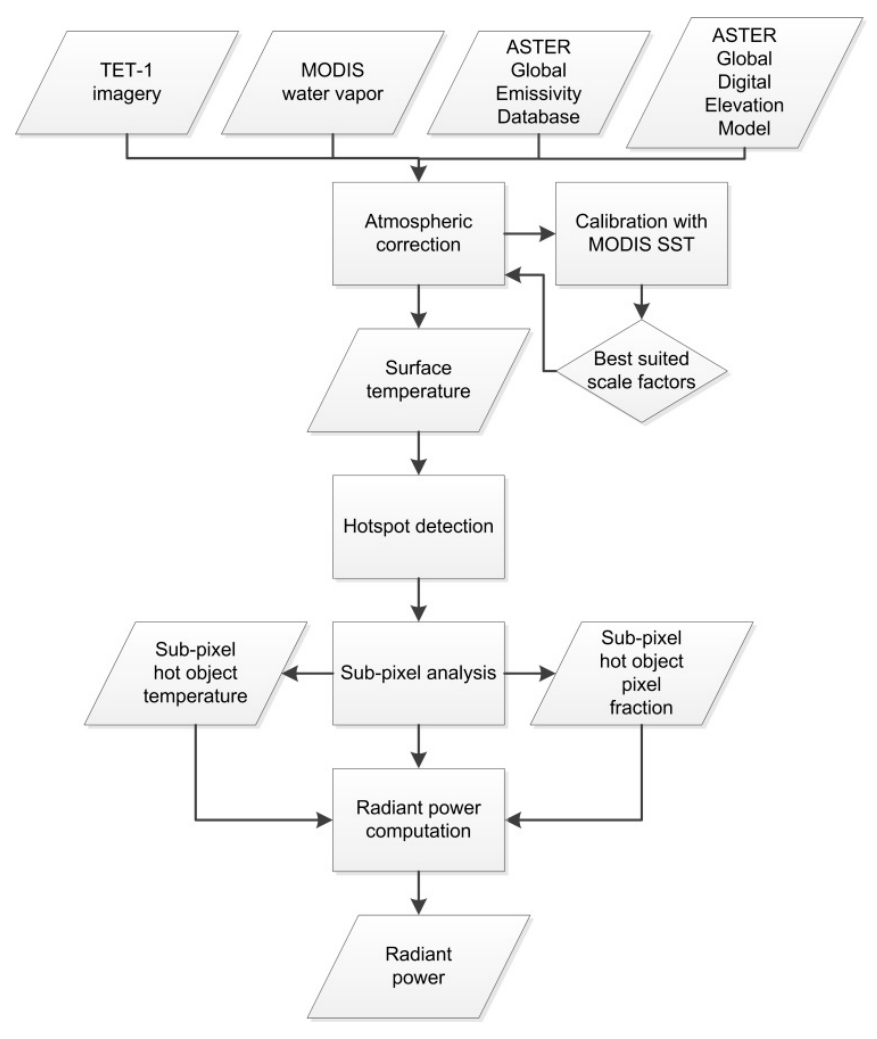

Figure 1. Workflow of the TET-1 image processing.

\subsubsection{Atmospheric Correction of TET-1 Thermal Imagery}

Radiometrically calibrated top-of-atmosphere (TOA) radiance data of TET-1 are used as input for the processing. The imagery is a stack of the coregistered nadir looking channels, i.e., the LWIR band and also the RED band in case of day time scenes, using the MWIR band as a master image.

To achieve surface radiances and temperatures in the MWIR and LWIR, the TET- 1 data has to be atmospherically corrected. The atmospheric correction is based on look-up tables derived from the MODTRAN-5 radiative transfer code [33]. Moreover, the following additional external information is used for the atmospheric correction. (1) Atmospheric water vapor strongly influences the signal. Due to the available channels of TET-1 (Table 2), water vapor cannot be derived directly from TET-1 data. Therefore, an external source was used to get information about the water vapor content during the time of the TET-1 acquisition. The MODIS water vapor product of the MODIS acquisition with the shortest temporal baseline to TET-1 acquisition is used for this purpose (Table 1). (2) Moreover, the Advanced Spaceborne Thermal Emission and Reflection Radiometer (ASTER) Global Digital Elevation 
Model (GDEM) is used during the atmospheric correction, as the water vapor also depends on the topographical elevation of the ground pixel.

(3) Another important factor in order to derive the TET-1 surface radiance is the emissivity of the surface. This data can be derived from the ASTER Global Emissivity Database (GED). Since ASTER has no MWIR channel, the emissivity can only be derived from data in the LWIR. For the applied processing, the emissivity of the ASTER bands $8.6 \mu \mathrm{m}$ and $9.1 \mu \mathrm{m}$ is used, because these bands match best with the LWIR of TET-1. Since a high spatial resolution global MWIR emissivity database is not available, the assumption of emissivity $\epsilon(M W I R)=1$ is often made. However, Salisbury and D'Aria [34], as well as Giglio et al. [35], indicate that the approximation $\epsilon(M W I R)=\epsilon(L W I R)$ is more realistic than $\epsilon(M W I R)=1$. Therefore, we employ this approximation, i.e., for the final processing of the surface radiance in LWIR and MWIR the same emissivity values are used. The atmospheric correction of the thermal TET-1 imagery is described in more detail in a past paper [36]. Next, according to the Planck's equation the surface radiance in LWIR and in MWIR is converted into the corresponding surface temperatures.

\subsubsection{Calibration by means of MODIS Sea Surface Temperature}

To control the radiometric quality of the TET- 1 thermal imagery, the atmospherically corrected TET-1 surface temperature was tested against the MODIS sea surface temperature (SST); as the temperature over sea surfaces is more homogenous than over land surfaces. Two of the nine TET-1 scenes analyzed in this study cover cloud-free areas over the sea. For these two TET-1 scenes, one was derived during day time and one during night time (bold in Table 1); the optimal scale factor was derived by minimizing the difference between the TET- 1 and the MODIS SST and consecutively applied to the radiometry. This was performed by an empirical test of different scale factors (cf. Section 3.1). These optimal scale factors for day and night time TET-1 scenes (cf. Section 3.1) were applied to all other day or night time TET-1 scenes, respectively (Table 1).

\subsubsection{Hotspot Detection and Subpixel Analysis}

Next, by using the background temperature $T_{b}$ and the bi-spectral approach from Dozier [37] one can estimate (I1) the subpixel temperature $T_{\text {sub }}$ of the hot areas and (2) the pixel fraction $p$ which is covered by a hot object. Thus, despite the relatively coarse resolution of TET-1 (around $356 \mathrm{~m}$ ), it is possible to derive the temperature of hot objects much smaller than a pixel (subpixel).

In addition, the radiant power $\Phi$ in watts $[\mathrm{W}]$ is derived as the difference of the power due to the subpixel temperature $T_{\text {sub }}$ and the background temperature $T_{b}$ using Wien's law (Equation (1)).

$$
\Phi=\sigma \epsilon\left(\mathrm{T}_{\text {sub }}^{4}-\mathrm{T}_{\mathrm{b}}^{4}\right) A_{\text {sub }}
$$

with $\sigma$ being the Stefan-Boltzmann constant $\left[\frac{\mathrm{W}}{\mathrm{m}^{2} \mathrm{~K}^{4}}\right], \epsilon$ being the LWIR emissivity and $A_{\text {sub }}\left(\mathrm{m}^{2}\right)$ being the subpixel area of the hot object, which is obtained from the pixel size and the fractional subpixel area $p$.

We compared the results of the proposed method with the results of the Zhukov approach [38] for different case studies and found a good agreement of the results of both approaches, e.g., Halle et al. [39].

\subsubsection{Detection of Surface Changes}

Besides the detection and analysis of high temperature events, the imagery of the TET- 1 mission is also suited for detection of larger changes on the Earth's surface due to volcanic eruptions. The March 2015 Villarrica eruption caused ash coverage of the glacier at the eastern flank. To detect the changes within the area covered by the glacier, the difference of the RED bands and the difference of 
the MWIR surface temperatures of the latest pre-event (22 February 2015, 17:23 UTC) and the next post-event, acquired at the same daytime (9 March 2015, 17:31 UTC), were computed.

\section{Results}

\subsection{Optimal Scale Factors}

The Tables 3 and 4 show the difference of the TET-1 SST and the MODIS SST for a day time and a night time TET-1 scene regarding different scale factors. The best suited scale factors, i.e., the ones with the lowest difference of TET- 1 and MODIS SST, are marked in bold. These optimal scale factors were then applied to all the other day or night time TET-1 scenes, respectively. Prior to this study, we compared SST from TET-1 and MODIS for a series of other study sites.

Table 3. Difference of the TET-1 and MODIS SST for day time TET-1 scene 25 April 2015 17:49 UTC, using a MODIS SST dataset acquired 23 min later.

\begin{tabular}{ccc}
\hline Scale Factor & MWIR $\boldsymbol{\Delta}$ MODIS SST to TET-1 SST (K) & LWIR $\boldsymbol{\Delta}$ MODIS SST to TET-1 SST (K) \\
\hline 1.00 & +2.84 & +2.33 \\
1.05 & +1.04 & $-\mathbf{0 . 6 2}$ \\
1.10 & $\mathbf{+ 0 . 0 2}$ & -3.48 \\
\hline
\end{tabular}

Table 4. Difference of the TET-1 and MODIS SST for night time TET-1 scene 21 March 2015 04:36 UTC, using a MODIS SST dataset acquired 26 min earlier.

\begin{tabular}{ccc}
\hline Scale Factor & MWIR $\boldsymbol{\Delta}$ MODIS SST to TET-1 SST (K) & LWIR $\boldsymbol{\Delta}$ MODIS SST to TET-1 SST (K) \\
\hline 1.00 & +4.07 & +4.98 \\
1.05 & +2.85 & +2.17 \\
1.10 & +1.54 & $-\mathbf{0 . 7 3}$ \\
1.15 & $\mathbf{+ 0 . 2 8}$ & -3.52 \\
\hline
\end{tabular}

Figure 2a shows the pre-eruption (22 February 2015) surface temperature derived from the MWIR channel after applying the atmospheric correction described in Section 2.2.1 in a 3D representation, using the optimal scale factors (cf. Tables 3 and 4). A TanDEM-X digital elevation model (DEM) is used as a source for the topographic information. At this daytime TET-1 scene, the cool glacier can very well be distinguished from the much warmer bare rock areas which are located at a lower elevation. The even lower elevated areas are covered by vegetation. For comparison, also see the false color Landsat- 8 image acquired on the same date (Figure 2b).

Snow and ice are characterized by a very high reflectivity of solar irradiation. In contrast to this, bare rocks have a much lower reflectivity and therefore a much higher absorption of solar irradiation. The absorbed solar energy shifted to longer wavelengths and was emitted as thermal energy. The reflectivity of vegetation lies in between the reflectivity of snow/ice and bare rocks. Therefore, bare rocks show a higher temperature.

Figure 3 shows the derived surface temperature for all nine TET- 1 acquisitions (cf. Table 1). The corresponding optimal scale factors of the Tables 3 and 4 were applied. One clearly sees a difference between the daytime and the night time acquisitions (cf. also Table 1). In contrast to the daytime image, the vegetation covered area shows slightly higher temperatures at night time than the bare rock areas, which cool down during the night. It is important to note that for all TET-1 MWIR surface temperature images the same minimum-maximum stretch was used, which makes the separation of bare rocks and vegetated areas in night time images more complicated, but enables a better comparison of the different acquisitions.

The change of the glacier coverage, visible when comparing Figure 3a,c is analyzed in Section 3.3. 
a)
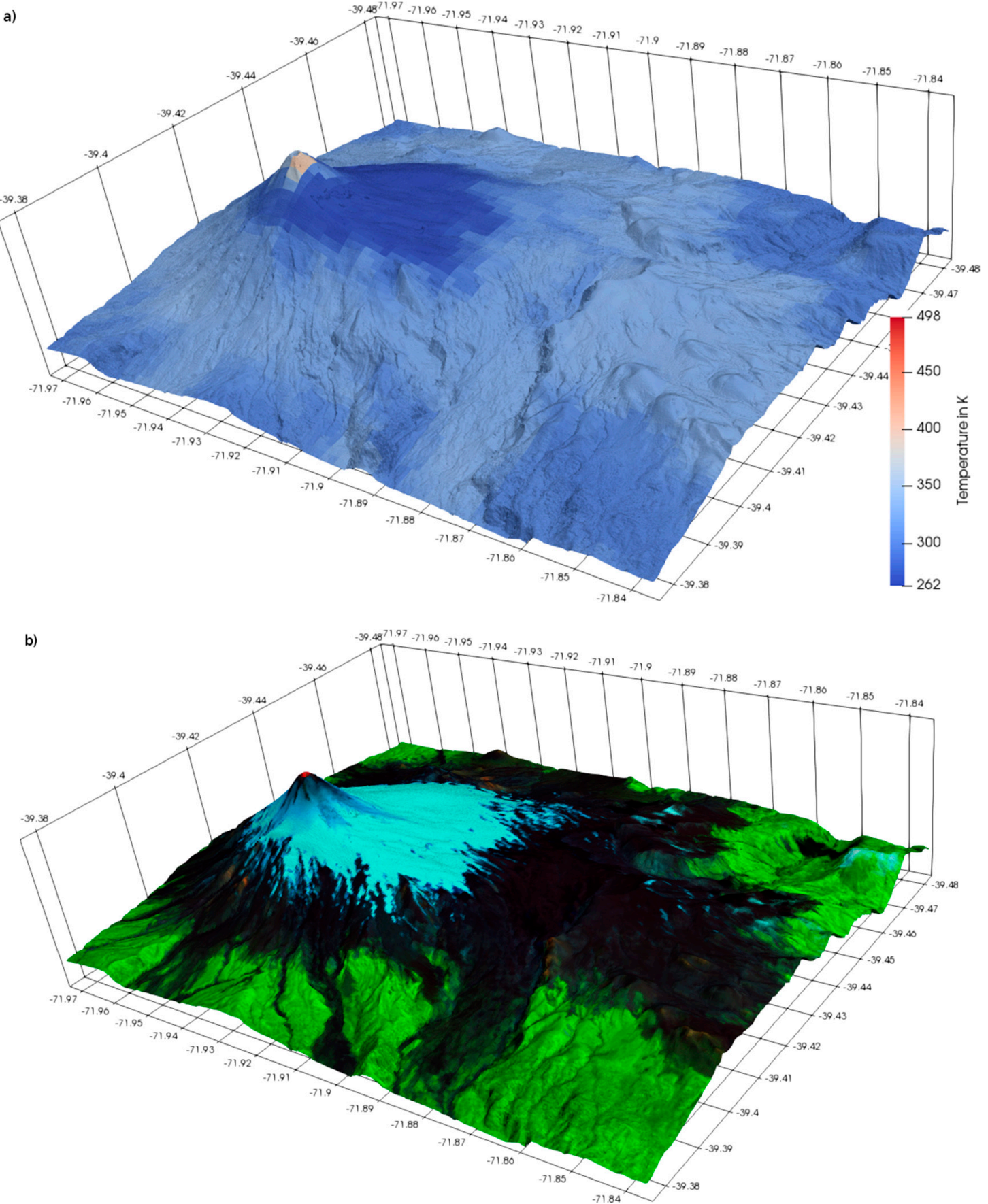

Figure 2. Villarrica Volcano observed on 22 February 2015: (a) The surface temperature derived from the atmospherically corrected TET-1 MWIR channel, overlaid on a TanDEM-X DEM. A minimum-maximum stretch over the observed values was applied. (b) Landsat-8 false color (SWIR2/NIR/GREEN) image, overlaid on a TanDEM-X DEM. The thermal hotspot at the Volcano summit is shown by red colors. Snow and ice covered areas appear in blue, bare rocks in black, and vegetated areas in green. 


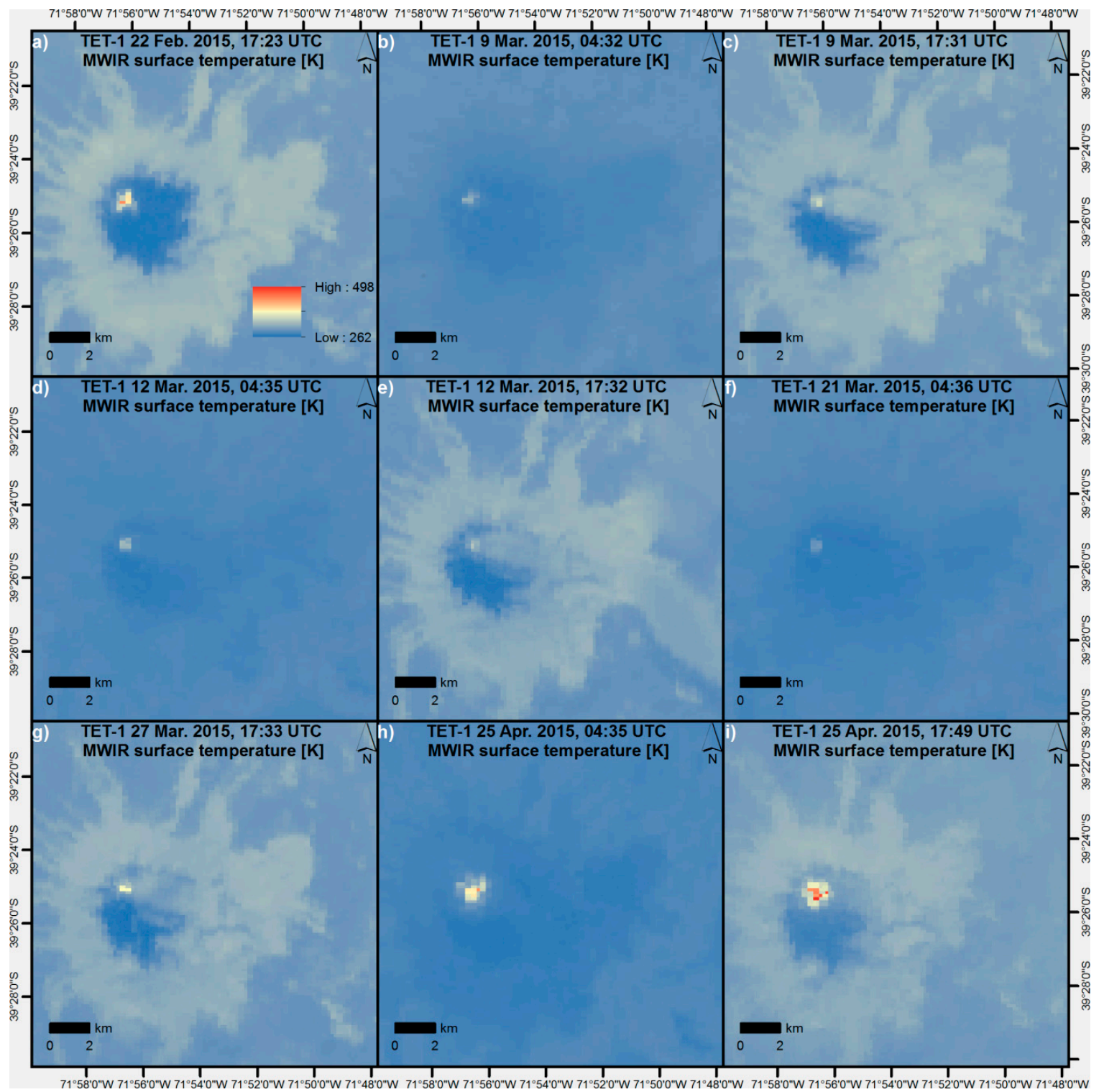

Figure 3. Surface temperature derived from the atmospherically corrected TET-1 MWIR channel. $(\mathbf{a}, \mathbf{c}, \mathbf{e}, \mathbf{g}, \mathbf{i})$ daytime acquisitions. (b,d,f,h) Night time acquisitions. The same minimum-maximum stretching of the surface temperature was applied to all images. The legend of figure (a) is valid for all TET-1 acquisitions.

\subsection{Hotspot Detection and Subpixel Analysis}

The MWIR surface temperature images (Figure 3) show the highest temperatures at the summit crater, with a strong temporal variation. We can see a strong signal in the 22 February 2015 image which was acquired nine days before the 3 March 2015 Villarrica Volcano eruption. After this first eruption, the summit crater still shows higher temperatures than the remaining part of the area of interest during all nine acquisitions dates. The 27 March 2015 scene and the two acquisitions on 25 April 2015, especially the one on 17:49 UTC, show a temperature increase at the summit crater. Figure 3 shows the surface temperature averaged within the area of each pixel.

The subpixel analysis, described in Section 2.2.3, provides more details on the temperature of the hot parts, such as liquid lava at the summit crater lava lake. Figure 4 shows the temperatures at subpixel level for the detected hot objects. Three hotspots with temperatures up to $572 \mathrm{~K}$ were detected 
at the pre-eruption TET-1 acquisition (22 February 2015). The hotspot temperatures measured from 9 to 12 March 2015 vary from $486 \mathrm{~K}$ to $592 \mathrm{~K}$. For the 21 March 2015 TET-1 acquisition, also showing the lowest MWIR surface temperatures (Figure 3f), no hotspots were detected. The acquisition of 27 March 2015 and the two acquisitions on 25 April 2015 show higher subpixel temperatures with up to $715 \mathrm{~K}, 828 \mathrm{~K}$, and $956 \mathrm{~K}$, respectively.

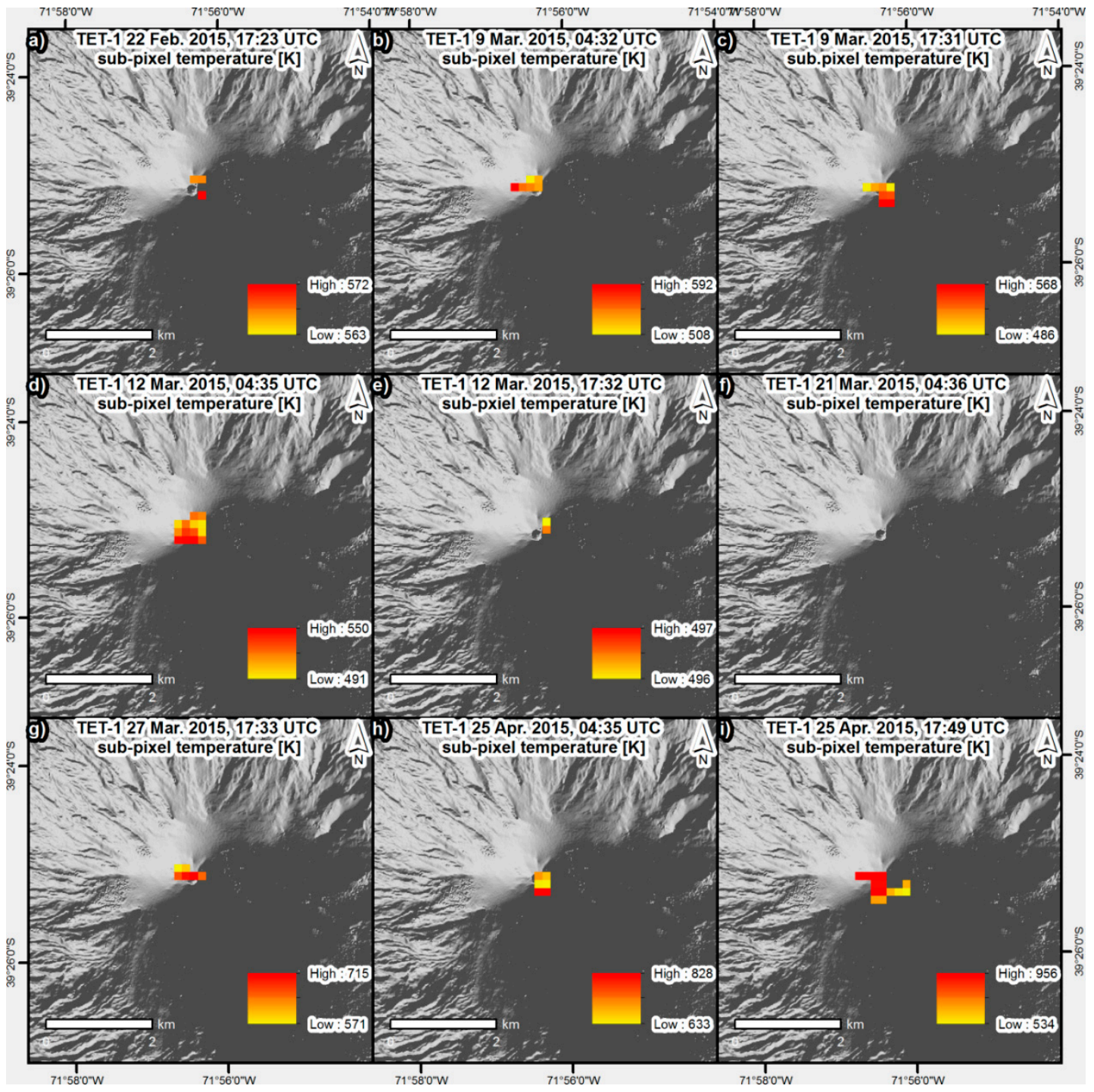

Figure 4. Subpixel temperatures of the hot areas at the summit crater derived from the nine TET-1 acquisitions (cf. Table 1). Background TanDEM-X DEM @ DLR.

Figure 5 shows the corresponding subpixel area for the aforementioned hotspots, i.e., the fraction of a pixel which is covered by the hotspot. Finally, the radiant power, derived from the subpixel temperature and the pixel fraction (cf. Section 2.2.3), is shown in Figure 6. The highest radiant power of a single pixel, amounting to $97 \mathrm{MW}$, was detected at the 25 April 2015 17:49 UTC TET-1 acquisition. Table 5 summarizes the radiant power integrated over all hotspot pixels detected within each TET-1 acquisition, restricted to the area of Villarrica Volcano. The integrated radiant power for the 25 April 2015, 17:49 UTC TET-1 acquisition is higher by the order of one magnitude compared to the other acquisitions. 


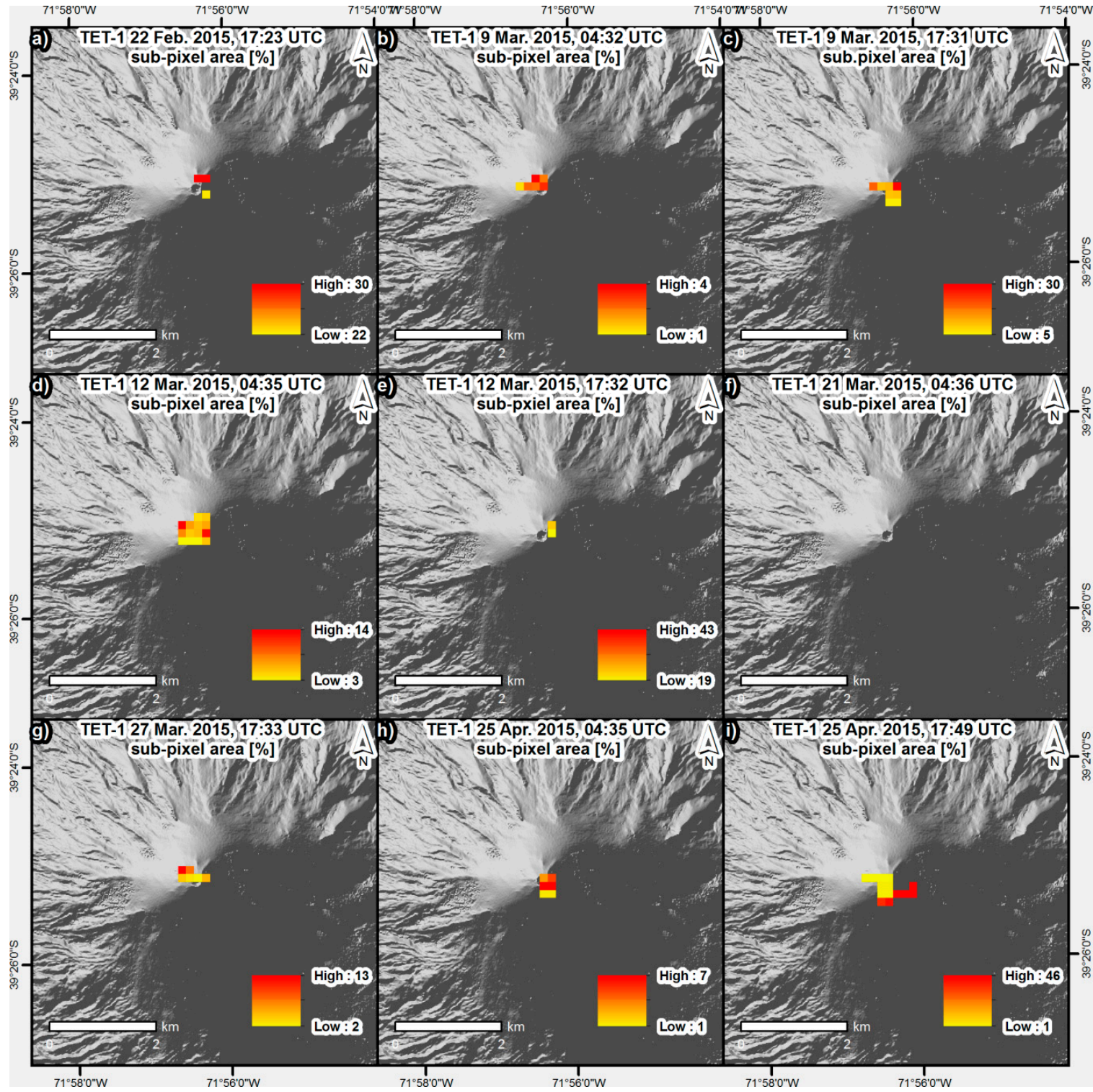

Figure 5. Subpixel area (percentage fraction of a pixel) of the hot areas at the summit crater derived from the nine TET-1 acquisitions (cf. Table 1). Background TanDEM-X DEM @ D DLR.

Table 5. Radiant power integrated over all detected hotspots. NO $=$ No hotspots detected on that date by the corresponding sensors.

\begin{tabular}{|c|c|c|c|c|c|}
\hline $\begin{array}{l}\text { TET-1 Acquisition Date \& Time } \\
\text { [UTC]; Off-Nadir Angle }\end{array}$ & $\begin{array}{c}\text { TET-1 } \\
\text { Integrated } \\
\text { Radiant Power } \\
{[\mathrm{MW}]}\end{array}$ & $\begin{array}{c}\text { MODIS } \\
\text { Acquisition: } \\
\text { Time } \\
\text { Difference to } \\
\text { TET-1 }\end{array}$ & $\begin{array}{c}\text { MODIS } \\
\text { Integrated } \\
\text { Radiant Power } \\
{[\mathrm{MW}]}\end{array}$ & $\begin{array}{c}\text { VIIRS } \\
\text { Acquisition: } \\
\text { Time } \\
\text { Difference to } \\
\text { TET-1 }\end{array}$ & $\begin{array}{c}\text { VIIRS } \\
\text { Integrated } \\
\text { Radiant Power } \\
{[\mathrm{MW}]}\end{array}$ \\
\hline 22 February $2015,17: 23 ;+19.4^{\circ}$ & 96.7 & -11 h $12 \mathrm{~min}$ & 24.3 & $-11 \mathrm{~h} 45 \mathrm{~min}$ & 32.7 \\
\hline 9 March $2015,04: 32 ;-21.9^{\circ}$ & 15.7 & - & NO & $+1 \mathrm{~h} 25 \mathrm{~min}$ & 4.1 \\
\hline 9 March $2015,17: 31 ;+6.0^{\circ}$ & 76.5 & - & NO & - & NO \\
\hline 12 March 2015, 04:35; $-20.5^{\circ}$ & 63.9 & - & NO & $+26 \min$ & 1.9 \\
\hline 12 March 2015, 17:32; +5.0 & 24.5 & - & NO & - & NO \\
\hline 21 March 2015, 04:36; -28.5 & NO & - & NO & - & NO \\
\hline 27 March 2015, 17:33; +4.2 ${ }^{\circ}$ & 56.7 & -11 h $47 \mathrm{~min}$ & 18.0 & - & NO \\
\hline 25 April 2015, 04:35; $+8.4^{\circ}$ & 62.4 & 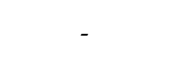 & NO & $\begin{array}{c}-4 \mathrm{~min} \\
+1 \mathrm{~h} 40 \mathrm{~min}\end{array}$ & $\begin{array}{c}1.9 \\
110.5\end{array}$ \\
\hline 25 April 2015, 17:49; - $18.0^{\circ}$ & 599.0 & $+23 \mathrm{~min}$ & 211.6 & - & NO \\
\hline
\end{tabular}




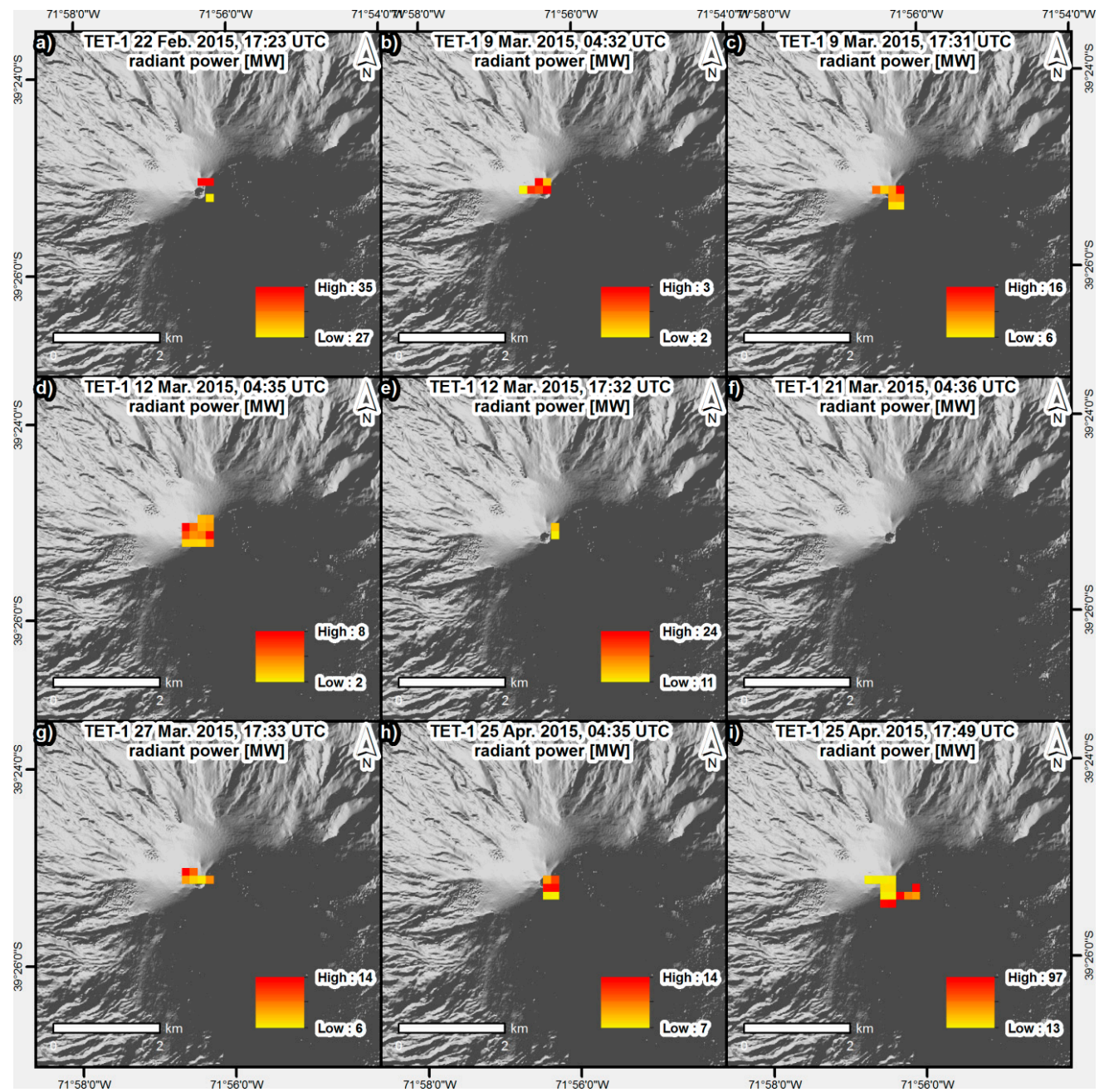

Figure 6. Radiant power of the hot areas at the summit crater derived from the nine TET-1 acquisitions (cf. Table 1). Background TanDEM-X DEM @ DLR.

In addition, Table 5 and Figure 7 show the integrated radiant power of the MODIS [40] and VIIRS [41] acquisitions (derived from [42]) of the corresponding TET-1 acquisition dates. This table is discussed in detail in Section 4.

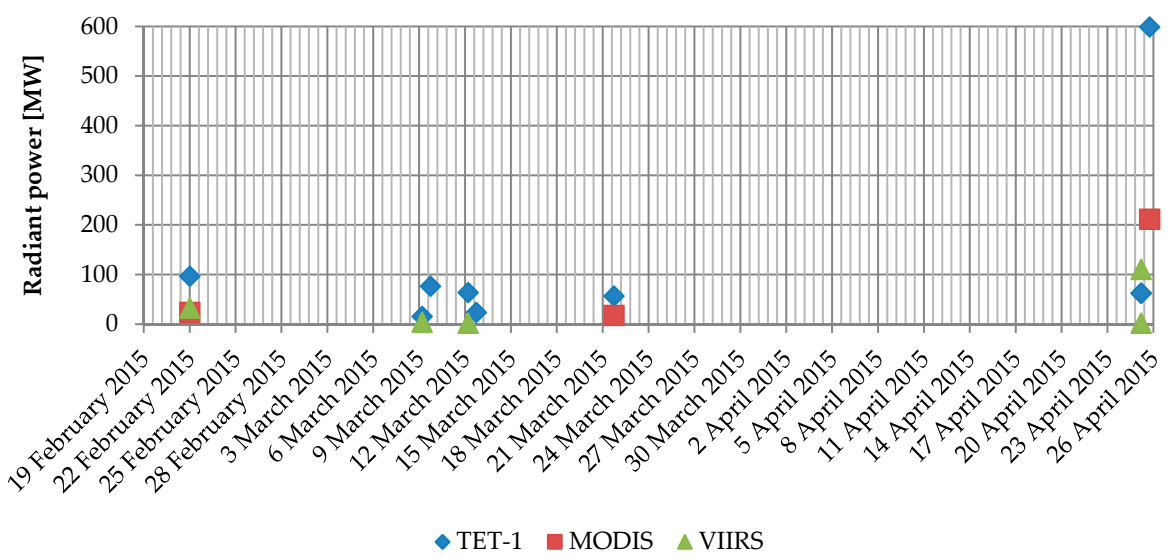

Figure 7. Temporal evolution of the radiant power integrated over all detected hotspots (cf. Table 5). 


\subsection{Detection of Surface Changes}

Figure 8 shows the RED band and the MWIR surface temperature of the latest pre-event (22 February 2015, 17:23 UTC) and the next post-event TET-1 scene acquired at the same daytime (9 March 2015, 17:31 UTC). Snow and ice coverage is generally characterized by high reflectivity in the RED band and lower thermal emission in the MWIR band. In the post-event images (Figure 8, second row), one clearly sees the decrease in the snow and ice covered area at the eastern flank of Villarrica Volcano. Figure 8g,h highlight this area in red, which was derived from the difference of the pre- and post-event MWIR surface temperature by setting a empirically derived threshold of $\Delta \geq 30 \mathrm{~K}$. An additional criterion was the decrease of the reflectivity of the RED TET- 1 channel.

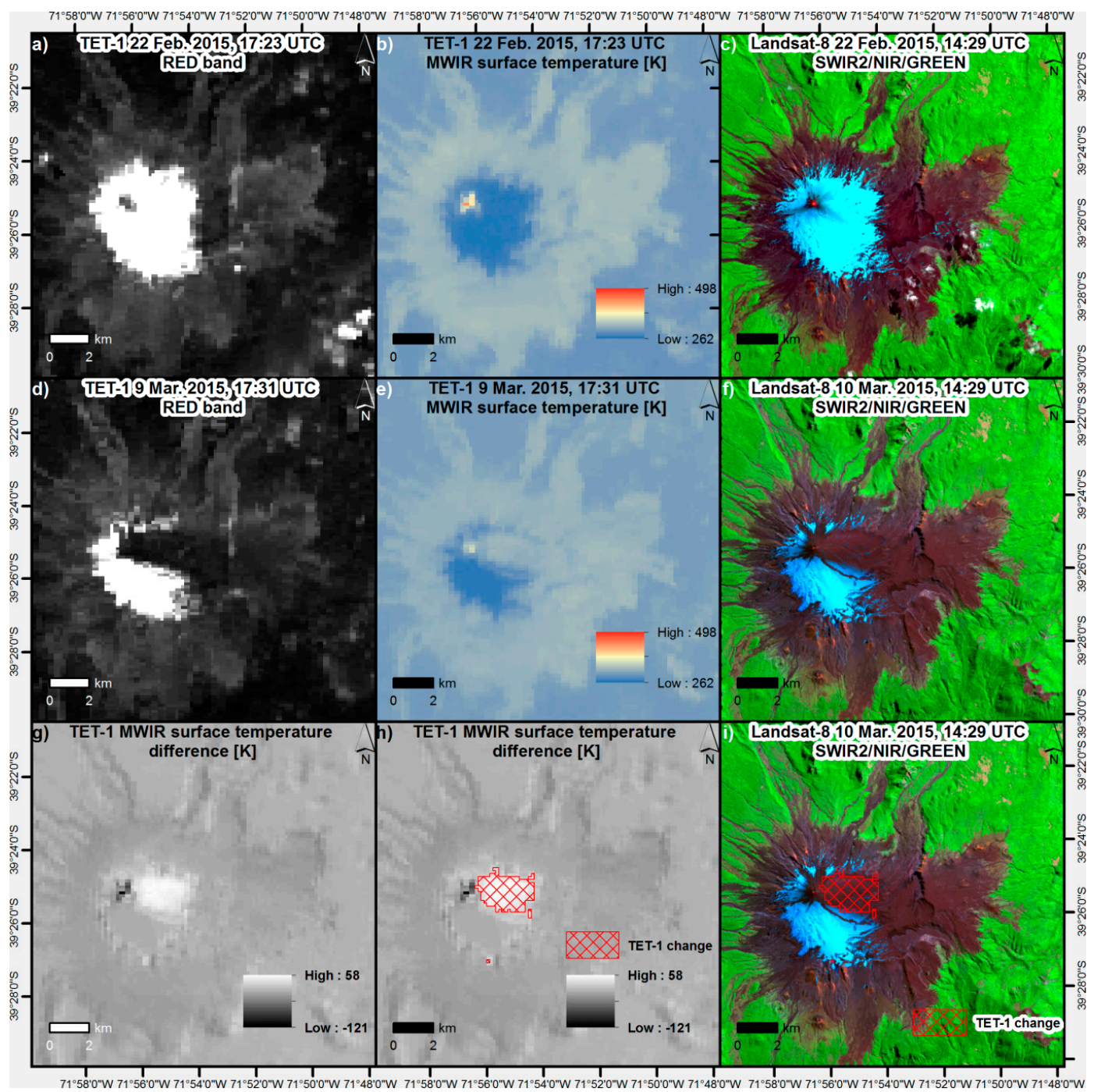

Figure 8. (a,d) RED band of the TET-1 pre-event (22 February 2015) and post-event (9 March 2015) acquisitions. (b,e) MWIR surface temperature of the TET-1 pre-event (22 February 2015) and post-event (9 March 2015) acquisitions. (c,f) False color composite (SWIR2/NIR/GREEN) of the Landsat-8 pre-event (22 February 2015) and post-event (10 March 2015) acquisitions. (g) Difference of the surface temperature of the pre- and post-event TET-1 MWIR bands. Detected change overlaid on the difference of the surface temperature of the pre- and post-event TET-1 MWIR bands (h) and on the post-event Landsat- 8 acquisition (i). 
The third column shows a false color composite of a pre-event (22 February 2015) and a post-event (10 March 2015) Landsat-8 acquisition as a reference. An overlay of the changed area derived from TET-1 MWIR data onto the Landsat-8 post-event scene acquired one day later shows a very good agreement between the detected change area and the area where the glacier was covered by ash due to the volcanic eruption.

\section{Discussion}

\subsection{Calibration by Means of MODIS Sea Surface Temperature}

To control the radiometric quality of the TET-1 data, a scale factor was applied as described in Section 2.2.2. By empirically testing different scale factors, the optimal scale factor was derived by minimizing the difference between the atmospherically corrected TET- 1 and the MODIS SST. We assume stable temperatures during the short time differences of less than $26 \mathrm{~min}$ between the TET- 1 and the corresponding MODIS acquisitions.

In the ideal case individual optimal scale factors should have been obtained from and applied to all single TET- 1 acquisitions. However, for only two of the nine TET- 1 acquisitions an area over the sea was free of clouds. Thus, optimal scale factors could be obtained only for these two TET-1 acquisitions. The optimal scale factor of the 25 April 2015, 17:49 UTC day time scene was applied to all other day time acquisitions. The optimal scale factor of the 21 March 2015, 04:36 UTC night time image was applied to all other night time scenes. Nevertheless, the Tables 3 and 4 show a very small derivation of the temperature differences between the two optimal scale factors for the day and night time scene. In addition, we see that even in the worst case of scale factor 1.00, meaning no 'correction' of the radiometry, the maximum difference between the TET- 1 and the MODIS SST was $5 \mathrm{~K}$. Therefore, we assume that reasonable scale factors were applied to all nine TET- 1 acquisitions analyzed in this study.

\subsection{Comparison with MODIS and VIIRS Hotspots}

Table 5 showed the integrated radiant power for each TET- 1 acquisition and also the one of the MODIS and VIIRS scenes acquired on the same dates for comparison. There are different reasons for a "missed" hotspot by MODIS or VIIRS, while thermal activity could be detected by TET-1. First, the volcano might be covered by clouds or a volcanic ash plume during an overfly of MODIS or VIIRS. Second, TET-1 is more sensitive for detection of thermal activity than the two other sensors, especially MODIS. Third, a different volcanic thermal activity can be assumed at the different acquisition times of the three sensors.

The following discusses the single acquisitions in more detail. The radiant power of the 22 February 2015, 17:23 UTC and the 27 March 2015 TET-1 acquisitions were not comparable with the corresponding radiant power derived from MODIS or VIIRS data, since the TET-1 acquisitions were taken more than $11 \mathrm{~h}$ later. However, the MODIS and VIIRS hotspots confirm the activity of Villarrica Volcano at these two dates.

The radiant power derived from the 9 March 2015, 04:32 UTC TET- 1 acquisition is in the same order of magnitude as the one derived from the corresponding VIIRS acquisition (05:57 UTC). In contrast to this, for the 12 March 2015, 04:35 UTC TET-1 scene there is a stronger difference with the corresponding VIIRS scene which was acquired 26 min later. However, both sensors, TET- 1 and VIIRS, confirm the thermal activity of Villarrica Volcano for that date.

On 21 March 2015, no hotspot was detected by TET-1. This matches the observations by VIIRS and MODIS. The TET-1 25 April 2015, 04:35 UTC shows a higher radiant power than the one derived from the VIIRS scene acquired 4 min earlier (04:31). However, a second VIIRS acquisition taken $1.5 \mathrm{~h}$ later shows a strong increase of the radiant power compared to the first VIIRS acquisition of that date. The radiant power measured by TET- 1 is in the middle between these two VIIRS acquisitions. Finally, the high thermal activity detected at the 25 April 2015, 17:49 UTC TET-1 acquisition was confirmed by 
the MODIS scene acquired 23 min later. However, the radiant power detected by TET- 1 is more than twice as high as the one measured by MODIS.

Overall, these aspects show the major differences of the obtained results, due to the different resolution (and sensitivity), and thus underlines the potential of high resolution thermal infrared sensor systems for this kind of investigation.

\subsection{Comparison with Independent Observations}

Moussallam et al. [1] reported that the lava lake at the Villarrica summit crater briefly disappeared on 25 February 2015 and reappeared at the surface on 28 March 2015. The analysis of the TET- 1 imagery showed lower radiant power values after the 3 March 2015 eruption than at the TET- 1 scene 22 February 2015, three days before the disappearance of the crater lava lake at the surface (cf. Section 3.2). Higher radiant power was again observed on the 25 April 2015, 17:49 UTC acquisition. The subpixel temperatures already showed for the 27 March 2015 TET-1 scene, i.e., one day before the reappearance of the crater lava lake at the surface, and the two following TET- 1 acquisitions on 25 April 2015, higher values than before.

\subsection{Influence of the Off-nadir Angle and the Depth/Width of the Crater}

As mentioned in Section 1.1, the lava lake at the funnel shaped summit crater of Villarrica Volcano is approximately $20 \mathrm{~m}$ to $30 \mathrm{~m}$ wide and located at depths of $50 \mathrm{~m}$ to over $150 \mathrm{~m}$ [15]. As the crater lava lake disappeared on 25 February 2015 (cf. Section 4.3) [1], these conditions are valid for the time before the 3 March 2015 eruption, i.e. for the 22 February 2015 TET-1 acquisition. The off-nadir angle of the center line of this TET-1 acquisition, where Villarrica Volcano is located, is $19.4^{\circ}$. The deeper the location of the crater lava lake, the smaller is the percentage of the crater lava lake which is visible for the TET-1 sensor. When assuming a crater lava lake width of $30 \mathrm{~m}$, the maximum depth of the crater lava lake (after which the full crater lava lake is in the shadow and not directly visible anymore for the TET-1 sensor under the aforementioned off-nadir angle) is approximately $90 \mathrm{~m}$ (maximum $60 \mathrm{~m}$ depth, for a width of $20 \mathrm{~m}$ ). Consequently, we can assume that a part of the crater lava lake was covered by shadow and not visible for the TET-1 sensor. Therefore, there is a high probability that the values of the radiant power presented in Section 3.2 were underestimated. Except for the aforementioned disappearance of the crater lava lake on 25 February 2015 and reappearance at the surface on 28 March 2015 [1], no further information about the depth of the crater lava lake was available for the time after the 3 March 2015 eruption. Nevertheless, we can also assume an influence of the depth of the crater lava lake on the measured radiant power at the other TET-1 acquisitions. Besides the depths of the crater lava lake, the type of volcanic activity (spanning from the lava lake to Strombolian) also influences the detectability from spaceborne sensors [43].

\subsection{Detection of Surface Changes}

Regarding the spatial resolution of the thermal channels and the repetition rate, the TET- 1 satellite is in between the class of the low spatial resolution/high repetition rate sensors, such as MODIS and Sentinel-3, and the class of high spatial resolution/lower repetition rate sensors such as Landsat-8. Its high flexibility and the aforementioned characteristics make the TET-1 satellite well-suited for rapid detection of larger changes at the Earth's surface. Section 3.3 showed the application of TET-1 data for the detection of the ash coverage of the Villarrica glacier caused by the 3 March 2015 eruption. This flexibility allowed TET- 1 to acquire the first image after the 3 March 2015 eruption earlier than the first available post-eruption Landsat- 8 acquisition.

We found that the difference of the pre- and post-event MWIR surface temperature is much better suited for the detection of changes in the glacier area than the difference of the reflectivity of the preand post-event RED bands. The best results could be obtained by a combined analysis of both channels. 


\section{Conclusions}

Villarrica Volcano is, with over 50 eruptions reported since the 16th century, one of the most active volcanoes of the South Andes Volcanic Zone. A time series of nine thermal images of the first satellite Technology Experiment Carrier-1 (TET-1) of the German Aerospace Center's (DLR) FireBIRD mission was analyzed to study the time before and after the 3 March 2015 eruption. We presented an atmospheric correction of the TET-1 data. The emissivity information was derived from the Advanced Spaceborne Thermal Emission and Reflection Radiometer (ASTER) Global Emissivity Database and the corresponding water vapor data from the Moderate Resolution Imaging Spectroradiometer (MODIS) acquisition with the shortest temporal baseline to the TET-1 acquisitions.

The detected thermal anomalies were investigated at subpixel level by deriving the subpixel temperature, the percentage area coverage of a pixel, and the radiant power. These observations were compared with hotspot information derived from MODIS and Visible Infrared Imaging Radiometer Suite (VIIRS) data. Analysis of TET-1 data showed thermal activity of Villarrica Volcano nine days before the 3 March 2015 eruption. The measured radiant power showed a decrease after this first eruption. An increase of the volcanic activity was again observed on 25 April 2015.

In addition to the analysis of the thermal hotspots at subpixel level, also the eruption-related ash coverage of the glacier at Villarrica Volcano was investigated by means of TET-1 imagery. The changes detected using TET-1 imagery matched well with the reference information derived from higher spatial resolution Landsat-8 imagery.

In summary, the information extracted from the thermal data of the flexible FireBIRD mission could be used in future to support and complement ground-based observations of active volcanoes.

Author Contributions: S.P. designed the experiments, performed the data analysis, and wrote the paper. R.R. supported the atmospheric correction of the TET-1 imagery. C.F. supported the TET-1 data analysis. M.N., S.M., T.R., E.S., and D.K. supported the study and provided suggestions for its improvement.

Funding: This research was funded, in part, by the German Federal Ministry of Education and Research (BMBF) under grant no. 03 G0876 (project RIESGOS).

Acknowledgments: The TanDEM-X DEM data was kindly provided by DLR (Proposal ID: DEM_GEOL1424). The authors would like to thank the three anonymous reviewers for their very constructive remarks.

Conflicts of Interest: The authors declare no conflicts of interest.

\section{References}

1. Moussallam, Y.; Bani, P.; Curtis, A.; Banie, T.; Moussellam, M.; Peters, N.; Schipper, C.I.; Aiuppa, A.; Giudice, G.; Amigo, A.; et al. Sustaining Persistent Lava Lakes: Observations from High-Resolution Gas Measurements at Villarrica Volcano, Chile. Earth Planet. Sci. Lett. 2016, 454, 237-247. [CrossRef]

2. Patrick, M.R.; Orr, T.; Sutton, A.J.; Lev, E.; Thelen, W.; Fee, D. Shallowly driven fluctuations in lava lake outgassing (gas pistoning), Kilauea Volcano. Earth Planet. Sci Lett. 2016, 433, 326-338. [CrossRef]

3. Bani, P.; Oppenheimer, C.; Tsanev, V.; Carn, S.; Cronin, S.; Crimp, R.; Calkins, J.; Charley, D.; Lardy, M.; Roberts, T. Surge in Sulphur and halogen degassing from Ambrym volcano, Vanuatu. Bull. Volcanol. 2009, 71, 115-1168. [CrossRef]

4. Rymer, H.; de Vries, B.V.; Stix, J.; Williams-Jones, G. Pit crater structure and processes governing persistent activity at Masaya Volcano, Nicaragua. Bull. Volcanol. 1998, 59, 345-355. [CrossRef]

5. Harris, A.J.L.; Flynn, L.P.; Rothery, D.A.; Oppenheimer, C.; Sherman, S.B. Mass flux Measurements at Active Lava Lakes: Implications for Magma Recycling. J. Geophys. Res. Solid Earth 1999, 104, 7117-7136. [CrossRef]

6. Sawyer, G.M.; Oppenheimer, C.; Tsanev, V.; Yirgu, G. Magmatic degassing at Erta 'Ale volcano, Ethiopia. J. Volcanol. Geotherm. Res. 2008, 178, 837-846. [CrossRef]

7. Calkins, J.; Oppenheimer, C.; Kyle, P.R. Ground-based thermal imaging of lava lakes at Erebus volcano, Antarctica. J. Volcanol. Geotherm. Res. 2008, 177, 695-704. [CrossRef]

8. Campion, R. New laval lake at Nyamuragira volcano revealed by combined ASTER and OMI SO2 measurements. Geophys. Res. Lett. 2014, 41, 7485-7492. [CrossRef] 
9. Coppola, D.; Campion, R.; Laiolo, M.; Cuoco, E.; Balagizi, C.; Ripepe, M.; Cigolini, C.; Tedesco, D. Birth of a lava lake: Nyamulagira volcano 2011-2015. Bull. Volcanol. 2016, 78. [CrossRef]

10. Rivera, A.; Bown, F. Recent glacier variations on active ice capped volcanoes in the Southern Volcanic Zone (37 $-46^{\circ}$ S), Chilean Andes. J. South Am. Earth Sci. 2013, 45, 345-356. [CrossRef]

11. Ripepe, M.; Marchetti, E.; Bonadonna, C.; Harris, A.J.L.; Pioli, L.; Ulivieri, G. Monochromatic infrasonic tremor driven by persistent degassing and convection at Villarrica Volcano, Chile. Geophys. Res. Lett. 2010, 37. [CrossRef]

12. Shinohara, H.; Witter, J.B. Volcanic gases emitted during mild Strombolian activity of Villarrica volcano, Chile. Geophys. Res. Lett. 2005, 32. [CrossRef]

13. Witter, J.B.; Kress, V.C.; Delmelle, P.; Stix, J. Volatile degassing, petrology, and magma dynamics of the Villarrica Lava Lake, Southern Chile. J. Volcanol. Geotherm. Res. 2004, 134, 303-337. [CrossRef]

14. Palma, J.L.; Calder, E.S.; Basualto, D.; Blake, S.; Rothery, D.A. Correlations between SO2 flux, seismicity, and outgassing activity at the open vent of Villarrica volcano, Chile. J. Geophys. Res. Solid Earth 2008, 113, B10. [CrossRef]

15. Aiuppa, A.; Bitetto, M.; Francofonte, V.; Velasquez, G.; Parra, C.B.; Giudice, G.; Liuzzo, M.; Moretti, R.; Moussallam, Y.; Peters, N.; et al. $\mathrm{CO}_{2}$-gas precursor to the March 2015 Villarrica volcano eruption. Geochem. Geophys. Geosyst. 2017, 18, 2120-2132. [CrossRef]

16. Goto, A.; Johnson, J.B. Monotonic infrasound and Helmholtz resonance at Volcan Villarrica (Chile). Geophys. Res. Lett 2011, 38, L06301. [CrossRef]

17. Bertin, D.; Amigo, A.; Bertin, L. Erupción del volcán Villarrica 2015: Productos emitidos y volumen involucrado. In Proceedings of the XIV Congreso Geológico Chileno, La Serena, Chile, 4-8 October 2015; Volume III, pp. 249-252.

18. Johnson, J.B.; Palma, J.L. Lahar infrasound associated with Volcán Villarrica's 3 March 2015 eruption. Geophys. Res. Lett. 2015, 42, 6324-6331. [CrossRef]

19. Harris, A.J.L.; De Groeve, T.; Carn, S.A.; Garel, F. Risk evaluation, Detection and Simulation during Effusive Eruption Disasters. In Detecting, Modelling and Responding to Effusive Eruptions; Harris, A.J.L., De Groeve, T., Garel, F., Carn, S.A., Eds.; Geological Society: London, UK, 2016; Volume 426, pp. 1-22. [CrossRef]

20. Harris, A.J.L. Effusive crisis at Piton de la Fournaise 2014-2015: A Review of a Multi-National Response Model. J. App. Volcanol. 2017, 6. [CrossRef]

21. Harris, A.J.L. Thermal Remote Sensing of Active Volcanoes. A User's Manual; Cambridge University Press: Cambridge, UK, 2013; p. 736. [CrossRef]

22. Blackett, M. An Overview on Infrared Remote Sensing of Volcanic Activity. J. Imaging 2017, 3, 13. [CrossRef]

23. Harris, A.J.L.; Baloga, S.M. lava discharge rates from satellite-measured heat flux. Geophys. Res. Lett. 2009, 36, L19302. [CrossRef]

24. Harris, A.J.L.; Dehn, J.; Calvari, S. Lava effusion rate definition and measurement: A Review. Bull. Volcanol. 2007, 70, 1-22. [CrossRef]

25. Wright, R.; Flynn, L.; Garbeil, H.; Harris, A.; Piler, E. Automated volcanic eruption detection using MODIS. Remote Sens. Environ. 2002, 82, 135-155. [CrossRef]

26. Kervyn, M.; Ernst, G.G.J.; Harris, A.J.L.; Belton, F.; Mbede, E.; Jacobs, P. Thermal remote sensing of the low-intensity carbonatite volcanism of Oldoinyo Lengai, Tanzania. Int. J. Remote Sens. 2008, 29, 6467-6499. [CrossRef]

27. Coppola, D.; Laiolo, M.; Cigolini, C.; Delle Donne, D.; Ripepe, M. Enhanced volcanic hot-spot detection using MODIS IR data: Results from the MIROVA system. In Detecting, Modelling and Responding to Effusive Eruptions; Harris, A.J.L., De Groeve, T., Garel, F., Carn, S.A., Eds.; Geological Society: London, UK, 2016; Volume 426. [CrossRef]

28. Coppola, D.; Laiolo, M.; Cigolini, C.; Orozco, G. The 2008 "Silent” Eruption of Nevados de Chillán (Chile) detected from space: Effusive rates and trends from the MIROVA system. J. Volcanol. Geotherm. Res. 2016, 327, 322-329. [CrossRef]

29. Spampinato, L.; Ganci, G.; Hernández, P.A.; Calvo, D.; Pérez, N.M.; Calvari, S.; Del Negro, C.; Yalire, M.M. Thermal insights into the dynamics of Nyiragongo lava lake from gound and satellite measurements. J. Geophys. Res. Solid Earth 2013, 118, 5771-5784. [CrossRef]

30. Blackett, M. Early Analysis of Landsat-8 Thermal Infrared Sensor Imagery of Volcanic Activity. Remote Sens. 2014, 6, 2282-2295. [CrossRef] 
31. Fischer, C.; Klein, D.; Kerr, G.; Stein, E.; Lorenz, E.; Frauenberger, O.; Borg, E. Data Validation and Case Studies using the TET-1 Thermal Infrared Satellite System. Int. Arch. Photogramm. Remote Sens. Spat. Inf. Sci. 2015, XL-7/W3, 1177-1182. [CrossRef]

32. Zakšek, K.; Hort, M.; Lorenz, E. Satellite and Ground Based Thermal Observation of the 2014 Effusive Eruption at Stromboli Volcano. Remote Sens. 2015, 7, 17190-171211. [CrossRef]

33. Berk, A.; Hawes, F.; van den Bosch, J.; Anderson, G.P. MODTRAN5.4.0 User's Manual; Spectral Sciences Inc.: Burlington, MA, USA, 2016.

34. Salisbury, J.W.; D'Aria, D.M. Emissivity of terrestrial materials in the 3-5 $\mu \mathrm{m}$ atmospheric window. Remote Sens. Environ. 1994, 47, 345-361. [CrossRef]

35. Giglio, L.; Kendall, J.D.; Justice, C.O. Evaluation of global fire detection algorithms using simulated AVHRR infrared data. Int. J. Remote Sens. 1999, 20, 1947-1985. [CrossRef]

36. Klein, D.; Richter, R.; Strobl, C.; Schläpfer, D. Solar Influence on Fire Radiative Power. IEEE Trans. Geosci. Remote Sens. under review.

37. Dozier, J. A method for satellite identification of surface temperature fields of subpixel resolution. Remote Sens. Environ. 1981, 11, 221-229. [CrossRef]

38. Zhukov, B.; Lorenz, E.; Oertel, D.; Wooster, M.; Roberts, G. Space-borne detection and characterization of fires during the bi-spectral infrared detection (BIRD) experimental small satellite mission (2001-2004). Remote Sens. Environ. 2006, 100, 29-51. [CrossRef]

39. Halle, W.; Asam, S.; Borg, E.; Fischer, C.; Frauenberger, O.; Lorenz, E.; Klein, D.; Nolde, M.; Paproth, C.; Plank, S.; et al. FireBIRD-small satellite or wild fire assessment. In Proceedings of the International Geoscience and Remote Sensing Symposium IGARSS, Valencia, Spain, 22-27 July 2018.

40. Justice, C.; Giglio, L.; Boschetti, L.; Roy, D.; Csiszar, I.; Morisette, J.; Kaufman, Y. Modis Fire Products; Algorithm Technical Background Document; NASA Goddard Space Flight Center: Greenbelt, MD, USA, 2006.

41. Visible Infrared Imaging Radiometer Suite (VIIRS) $375 \mathrm{~m}$ Active Fire Detection and Characterization Algorithm Theoretical Basis Document 1.0. Available online: https:/ /viirsland.gsfc.nasa.gov /PDF/VIIRS_ activefire_375m_ATBD.pdf (accessed on 19 June 2018).

42. NASA. Fire Information for Resource Management System (FIRMS). Available online: https:/ firms.modaps. eosdis.nasa.gov (accessed on 19 June 2018).

43. Aiuppa, A.; Maarten de Moor, J.; Arellano, S.; Coppola, D.; Francofonte, V.; Galle, B.; Giudice, G.; Liuzzo, M.; Mendoza, E.; Saballos, A.; et al. Tracking Formation of a Lava Lake from Ground and Space: Masaya Volcano (Nicaragua), 2014-2017. Geochem. Geophys. Geosys. 2018, 19, 496-515. [CrossRef] 